\title{
Hypoxia-induced increases in A549/CDDP cell drug resistance are reversed by RNA interference of HIF-1 $\alpha$ expression
}

\author{
LINGFENG MIN ${ }^{1,2^{*}}$, QIONG CHEN $^{2 *}$, SHUYA HE $^{1}$, SHENGGANG LIU $^{2}$ and YUN MA ${ }^{1}$ \\ ${ }^{1}$ Department of Biochemistry and Molecular Biology, University of South China, Hengyang 421001; \\ ${ }^{2}$ Department of Geriatric Medicine, Department of Respiratory, Xiangya Hospital of Central South University, \\ Changsha 410008, P.R. China
}

Received July 9, 2011; Accepted September 26, 2011

DOI: $10.3892 / \mathrm{mmr} .2011 .604$

\begin{abstract}
This study aimed to investigate the effects of knocking down hypoxia-inducible factor-1 $\alpha$ (HIF-1 $\alpha)$ through RNA interference on hypoxia-induced increases in drug resistance in A549/CDDP cells, and to study the underlying mechanisms. A small interfering RNA (siRNA) eukaryotic expression vector targeting HIF-1 $\alpha$ was constructed and transfected into A549/CDDP cells treated with hypoxia. The mRNA and protein levels of HIF-1 $\alpha$, multidrug resistance-1 (MDR1), and multidrug resistance-associated protein (MRP) were determined by reverse transcription polymerase chain reaction (RT-PCR) and immunocytochemistry. Cell viability following treatment with cisplatin was determined by MTT assay. Hypoxia increased the resistance of A549/CDDP cells to cisplatin and this effect was reversed by the siRNA inhibition of HIF-1 $\alpha$ expression. Expression of HIF-1 $\alpha$ siRNA also downregulated HIF-1 $\alpha$, MDR1 and MRP mRNA, and protein expression in A549/CDDP cells treated with hypoxia $(\mathrm{p}<0.05)$. Hypoxia-induced resistance of A549/CDDP cells to cisplatin is reversed by the siRNA inhibition of HIF-1 $\alpha$ expression. This effect may be mediated by a decreased expression of MDR 1 and MRP.
\end{abstract}

\section{Introduction}

Lung cancer, one of the most prevalent malignant tumors in the world, is commonly treated by chemotherapy. However, multidrug resistance (MDR) of lung cancer cells often leads to a failure of chemotherapy and is an issue that should be addressed. Expression of MDR1 and multidrug resistanceassociated protein (MRP) is closely related to MDR in lung

Correspondence to: Professor Shuya He, Department of Biochemistry and Molecular Biology, University of South China, Hengyang 421001, P.R. China

E-mail: skyhe2000@hotmail.com

*Contributed equally

Key words: small interfering RNA, hypoxia-inducible factor- $1 \alpha$, multidrug resistance-1, multidrug resistance-associated protein cancer cells, and inhibiting the expression of these proteins is capable of reversing MDR (1). Hypoxia-inducible factor-1 $\alpha$ (HIF-1 $\alpha$ ), a transcription factor widely expressed in human and animal cancer cells under hypoxic conditions (2), has been shown to increase the expression of proteins that confer MDR, including MDR1 and MRP $(3,4)$. In the current study, we examined the effects of a HIF- $1 \alpha$-small interfering RNA (siRNA) eukaryotic expression vector targeting HIF-1 $\alpha$ and transfected into the A549/CDDP-induced expression of MDR1 and MRP, and resistance to cisplatin in A549/CDDP cells.

\section{Materials and methods}

Cells. A549/CDDP cells (a cisplatin-resistant human lung adenocarcinoma cell line) were purchased from the Cell Center of Xiangya School of Medicine, Central South University (Changsha, China).

Reagents. Antibodies to HIF-1 $\alpha$, MDR1 and MRP were purchased from Beijing Zhongshan Golden Bridge Biotechnology Company (China). All other reagents were purchased from Invitrogen (USA).

HIF-1 $\alpha$-targeted siRNA. SiRNA was synthesized at Guangzhou Rainbow Biotechnology Company (Guangdong, China). We designed a siRNA oligonucleotide sequence (AAGAGGTGGATATGTCTGG) that, according to the sequence of human HIF-1 $\alpha$ (GenBank Accession No. 22431), targets a region with a GC content of 40-55\%. According to the sequence of the siRNA, a pair of complementary oligonucleotide chains encoding a short hairpin siRNA were designed (AAGAGGUGGAUAUGUCUGGUUC UCCACCUAUACAGACC). A negative control siRNA was also synthesized.

Cell culture and hypoxia treatment. A549/CDDP cells were cultured in RPMI-1640containing $10 \%$ fetal bovine serum. Cells were treated with $200 \mu \mathrm{mol} / \mathrm{ml} \mathrm{CoCl}_{2}$ to induce chemical hypoxia (5) and were harvested when cell growth was in the logarithmic phase.

Transfection of A549/CDDP cells. A549/CDDP cells (1x10 $)$ were seeded into 6 -well plates. After $24 \mathrm{~h}$, the cells were washed 
twice with serum-free RPMI-1640 and divided into 4 groups: i) control (cultured with RPMI-1640 alone); ii) hypoxia-treated (cultured with RPMI-1640 containing 10\% fetal bovine serum and $200 \mu \mathrm{mol} / \mathrm{ml} \mathrm{CoCl}_{2}$ ); iii) hypoxia-treated and control siRNA and iv) hypoxia-treated and HIF-1 $\alpha$ siRNA. For groups 3 and 4, cells were cultured with RPMI-1640 containing $10 \%$ fetal bovine serum and $200 \mu \mathrm{mol} / \mathrm{ml} \mathrm{CoCl}_{2}$ for $24 \mathrm{~h}$ until $30-50 \%$ confluence was achieved. The culture medium was then replaced with $1.5 \mathrm{ml}$ optimal medium and $1 \mathrm{~h}$ later transfection was performed according to the manufacturer's instructions. Lipofectamine ${ }^{\mathrm{TM}} 2000$ (Invitrogen) was used at a concentration of $10 \mathrm{~mol} / \mathrm{l}$ and plasmid concentration was 4 $\mathrm{mg} / \mathrm{l}$. After 4-6 h, the transfection medium was replaced with RPMI-1640 containing 10\% fetal bovine serum. Transfection efficiency was determined by fluorescence microscopy $24 \mathrm{~h}$ following transfection and cells were harvested after $48 \mathrm{~h}$.

Analysis of cisplatin resistance by MTT assay. A549/CDDP cells $\left(5 \times 10^{3}\right)$ were seeded into 96-well plates, and after $24 \mathrm{~h}$, cisplatin was added at varying concentrations $(0,10,40,80,100$ and $200 \mu \mathrm{mol} / \mathrm{l})$. Each concentration was tested in quadruplicate. After 72 -h of treatment, $10 \mu \mathrm{l}$ of MTT solution $(5 \mathrm{mg} / \mathrm{ml})$ was added to each well. This was followed $4 \mathrm{~h}$ later by the addition of $200 \mu \mathrm{l}$ of dimethyl sulfoxide (DMSO) to each well and the culture plate was then placed on an orbital shaker for $10 \mathrm{~min}$ to completely dissolve the formazan blue granules. The optical density at $570 \mathrm{nM}\left(\mathrm{OD}_{570}\right)$ was then measured using a microplate reader. Inhibition of cell growth was calculated as: $1-\mathrm{OD}_{570}$ of the experimental group/OD ${ }_{570}$ of the control group and the median effective concentration $\left(\mathrm{IC}_{50}\right)$ for cisplatin was calculated by weighted linear regression (6). The relative reversal rate was calculated as: $1-\mathrm{IC}_{50}$ of treatment group/ $\mathrm{IC}_{50}$ of the control group.

Reverse transcription polymerase chain reaction ( $R T-P C R)$. Total RNA was isolated and reverse transcribed, followed by 32 cycles of RT-PCR. The primer sequences used were: MDR1 (product: $334 \mathrm{bp}$ ) forward: 5'-GAAGGAAAAGAAAC CAAC-3' and reverse: 5'-CAGGCACCAAAATGAAAC-3'; MRP (product: $314 \mathrm{bp)} \mathrm{forward:} \mathrm{5'-TCGCTCACCCCTG}$ TTCTC-3' and reverse: 5'-CCACCTCCTCATTCG CAT-3'; HIF-1 $\alpha$ (product: 436 bp) forward: 5'-ATACCAA CAGTAACCAACCT-3' and reverse: 5'TGAATAATA CCACTCACAAC-3'; $\beta$-actin (product: $170 \mathrm{bp}$ ) forward: 5'-CTGGCACCACACCTTCTACAATGAGC-3' and reverse: 5'-GGGATA GCACAGCCTGGATAGCAACG-3'. Primers were synthesized at Sangon Biotech (Shanghai, China). PCR products were separated by electrophoresis in a $2.0 \%$ agarose gel and the product bands were analyzed using a digital gel imaging system.

Analysis of HIF-1 $\alpha, M D R 1$ and MRP protein expression. The expression of HIF-1 $\alpha$, MDR1 and MRP proteins was analyzed using the immunocytochemistry SP method. An antibody titer of 1:100 for HIF-1 $\alpha$, MDR1 and MRP was used. Following attachment to glass coverslips, cells were fixed using $4 \%$ paraformaldehyde, washed 3 times with phosphate-buffered saline (PBS), treated with $3 \% \mathrm{H}_{2} \mathrm{O}_{2}$ at room temperature for $15 \mathrm{~min}$, washed again 3 times with PBS and then preblocked with goat serum at room temperature for $15 \mathrm{~min}$. The cells were then incubated with primary antibodies at $4^{\circ} \mathrm{C}$ overnight, washed 3 times with PBS, incubated with biotin-labeled secondary antibodies at room temperature for $20 \mathrm{~min}$, and again washed 3 times with PBS. The cells were then incubated with peroxidaseconjugated streptavidin working solution at room temperature for $20 \mathrm{~min}$, followed by diaminobenzidine (DAB) staining, hematoxylin-restaining, dehydration and mounting. A total of 500 cells were counted in 5 random visual fields under a microscope at a magnification of $\mathrm{x} 400$, and the percentage of positive cells was calculated as cells with positive cytoplasmic staining/total cells. The percentage of positive cells was graded as follows: $0,<5 \% ; 1,5-25 \% ; 2,25-50 \% ; 3,50-75 \%$ and $4,>75 \%$. Staining intensity was graded as follows: 0 , blank and unstained; 1, weak and faint yellow; 2, medium and yellow or deep yellow and 3 , strong and brown or reddish brown. Protein expression levels were calculated as the sum of the grades for staining intensity and the percentage of positive cells (7).

Statistical analysis. Statistical analysis was performed using SPSS 12.0 and results were expressed as the mean \pm standard deviation (SD). Comparison of multiple sample means was performed using the Student-Newman-Keuls-q (SNK-q) test. Two-factor and two-level data were analyzed by analysis of variance for factorial design. A correlation between two sets of data was performed using the rank correlation (Spearman test). Statistical analyses were two-sided, with $\mathrm{p}<0.05$ being considered as significant.

\section{Results}

Effect of HIF-1 $\alpha$ siRNA on the sensitivity of A549/CDDP cells to cisplatin. The results of the MTT assay revealed that the $\mathrm{IC}_{50}$ for cisplatin in A549/CDDP cells after $72 \mathrm{~h}$ treatment was $396.16 \pm 15.63 \mu \mathrm{mol} / \mathrm{l}$; the $\mathrm{IC}_{50}$ in the hypoxia-treated group was $453.87 \pm 11.26 \mu \mathrm{mol} / 1(\mathrm{p}<0.05)$; the $\mathrm{IC}_{50}$ in the hypoxia- and control siRNA-treated group was $463.89 \pm 12.89 \mu \mathrm{mol} / \mathrm{l}$; and the $\mathrm{IC}_{50}$ in the hypoxia- and HIF-1 $\alpha$ siRNA-treated group was $234.63 \pm 13.21 \mu \mathrm{mol} / \mathrm{l}$ (Table I). The relative reversal rate in HIF-1 $\alpha$ siRNA-treated cells was calculated as $48 \%$, indicating that hypoxia increases the resistance of A549/CDDP cells to cisplatin and that this could be reversed by treatment with HIF-1 $\alpha$ siRNA.

Effects of hypoxia and HIF-1 $\alpha$ siRNA on the expression of HIF-1 $\alpha$ mRNA in A549/CDDP cells. HIF-1 $\alpha$ mRNA expression was measured $48 \mathrm{~h}$ following transfection with siRNA (Fig. 1).HIF-1 $\alpha$ mRNA was expressed in all 4 treatment groups and was increased under conditions of hypoxia. Treatment with HIF-1 $\alpha$ siRNA reversed the hypoxia-induced increase in HIF-1 $\alpha$ mRNA expression $(\mathrm{p}<0.05)$.

Effects of hypoxia and HIF-1 $\alpha$ siRNA on the expression of MDR1 and MRP $m R N A$ in A549/CDDP cells. MDR1 and MRP mRNA expression levels were measured $48 \mathrm{~h}$ following transfection with siRNA (Fig. 2). MDR1 and MRP mRNAs were expressed in all 4 treatment groups and were increased by hypoxia treatment. Treatment with HIF-1 $\alpha$ siRNA reversed the hypoxia-induced increase in expression of MDR1 and MRP mRNAs $(\mathrm{p}<0.05)$. Spearman's rank correlation analysis revealed that the expression of HIF-1 $\alpha$ mRNA was positively 
Table I. The effect of HIF- $1 \alpha$ siRNA on the sensitivity of A549/CDDP cells to cisplatin (mean \pm SD, $n=4$ ).

Group $\quad \mathrm{IC}_{50}(\mu \mathrm{mol} / \mathrm{l}) \quad$ Relative reversal rate

\section{Control}

Hypoxia-treated

Hypoxia- and control siRNA-treated

Hypoxia- and HIF-1 $\alpha$-siRNA-treated

$$
\begin{aligned}
& 396.16 \pm 15.63 \\
& 453.87 \pm 11.26^{\mathrm{a}} \\
& 463.89 \pm 12.89 \\
& 234.63 \pm 13.21^{\mathrm{a}, \mathrm{b}}
\end{aligned}
$$

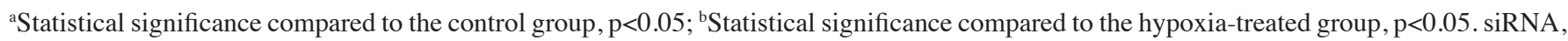
small interfering RNA; HIF-1 $\alpha$, hypoxia-inducible factor $1 \alpha$.

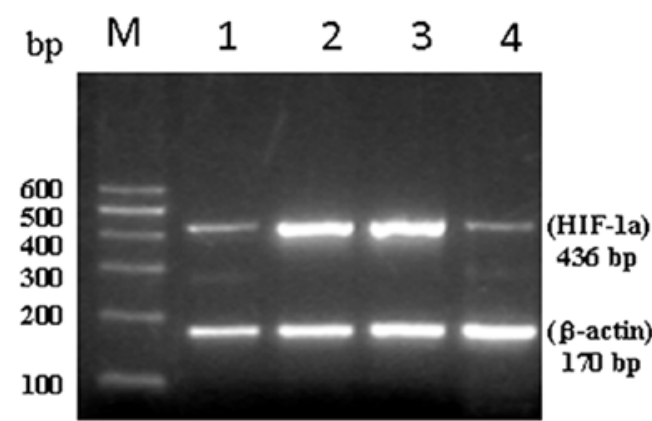

B

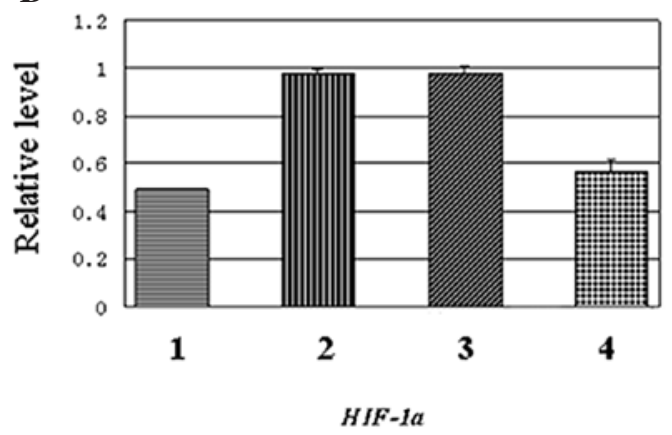

Figure 1. The effects of hypoxia and HIF-1 $\alpha$ siRNA on the expression of HIF-1 $\alpha$ mRNA in A549/CDDP cells. (A) The expression of HIF-1 $\alpha$ mRNA was measured by RT-PCR. M, 100-bp DNA marker; lane 1, control group; lane 2, hypoxia-treated group; lane 3, hypoxia-treated and control siRNA group; lane 4, hypoxia- and HIF-1 $\alpha$ siRNA-treated group. (B) Quantification of results shown in (A). HIF-1 $\alpha$, hypoxia-inducible factor 1 $\alpha$; siRNA, small interfering RNA; RT-PCR, reverse transcription polymerase chain reaction.

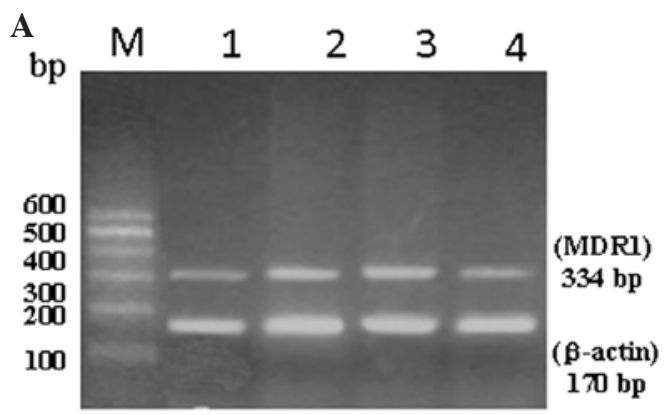

C

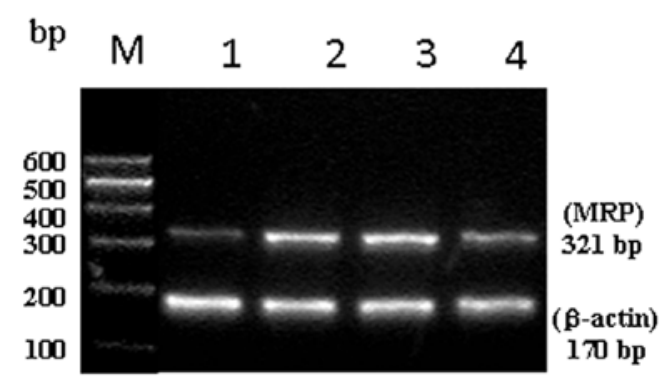

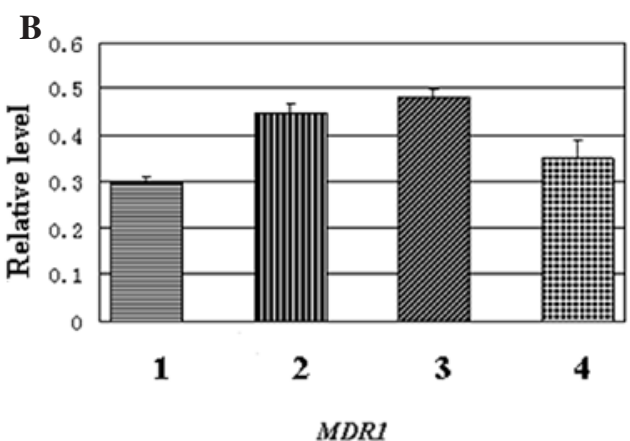

D

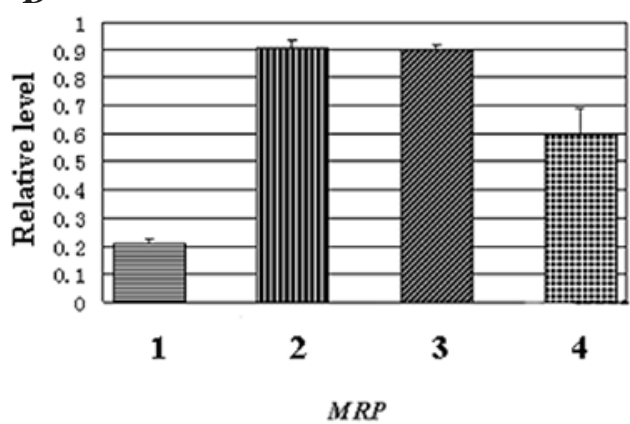

Figure 2. The effects of hypoxia and HIF-1 $\alpha$ siRNA on the expression of MDR1 and MRP mRNAs in A549/CDDP cells. (A and C) The expression of MDR1 and MRP mRNA was measured by RT-PCR. M, DNA bp ladder; lane 1, control group; lane 2, hypoxia-treated group; lane 3, hypoxia- and control siRNA-treated group; lane 4, hypoxia- and HIF-1 $\alpha$ siRNA-treated-group. (B and D) Quantification of results shown in (A and C). MDR1, multidrug resistance-1; MRP, multidrug resistance-associated protein; HIF-1 $\alpha$, hypoxia-inducible factor $1 \alpha$; siRNA, small interfering RNA; RT-PCR, reverse transcription polymerase chain reaction. 


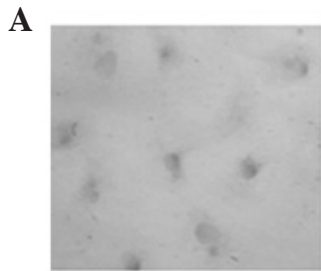

C

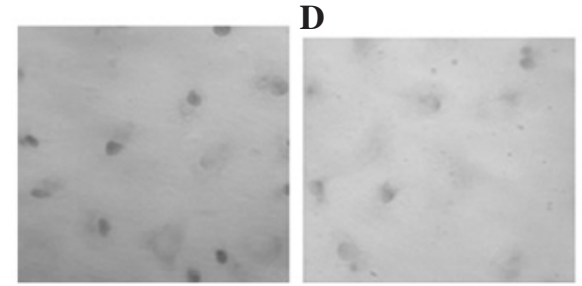

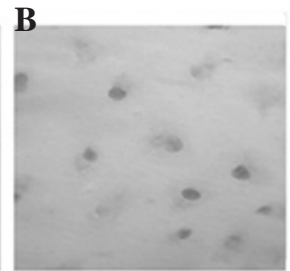

D

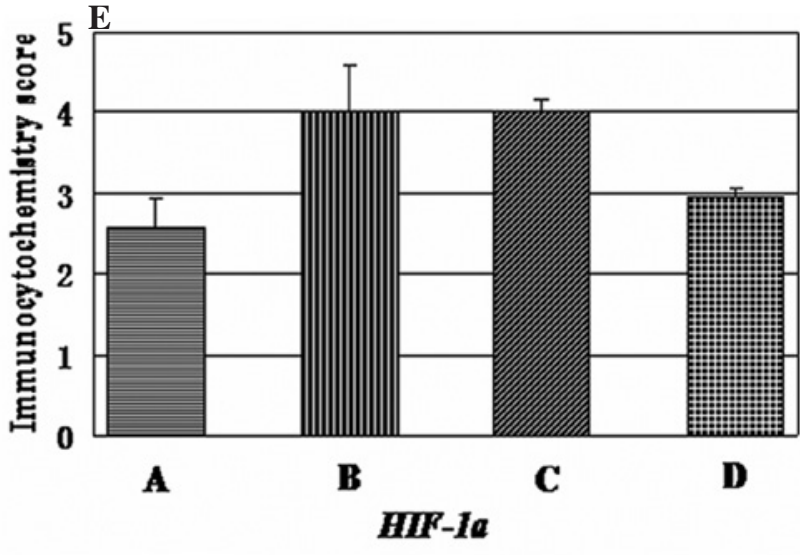

Figure 3. The effects of hypoxia and HIF-1 $\alpha$ siRNA on the expression of HIF-1 $\alpha$ protein in A549/CDDP cells. (A-D) The expression of HIF-1 $\alpha$ protein was analyzed by immunocytochemistry. (A) Control group; (B) hypoxia-treated group; (C) hypoxia- and control siRNA-treated group; (D) hypoxia- and HIF-1 $\alpha$ siRNA-treated group. (E) Grading of positive protein staining in all 4 groups. HIF-1 $\alpha$, hypoxia-inducible factor 1 $\alpha$; siRNA, small interfering RNA.

A

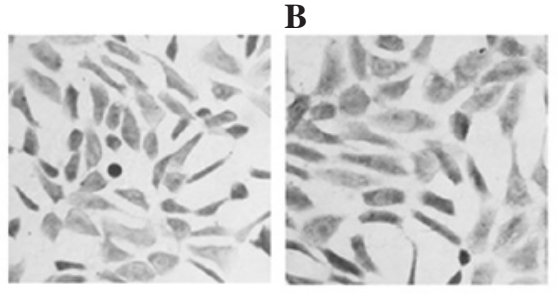

C

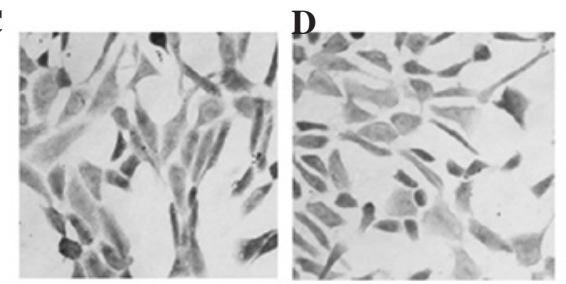

E

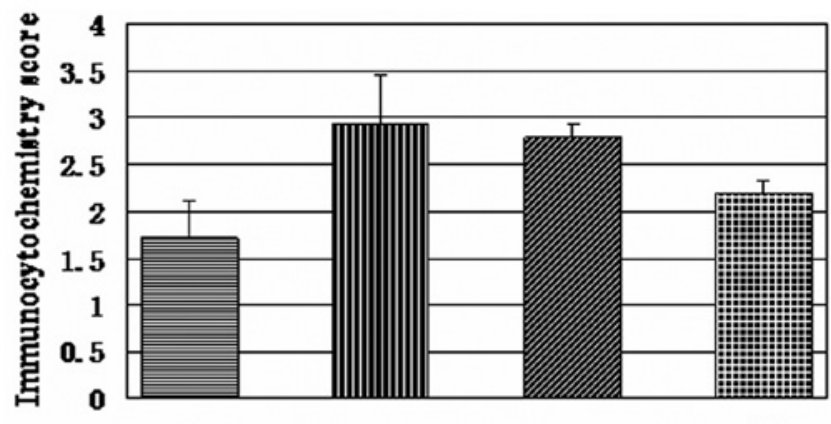

$\mathbf{A}$
$\mathbf{C}$
D

Figure 4. The effects of hypoxia and HIF-1 $\alpha$ siRNA on the expression of MDR1 protein in A549/CDDP cells. (A-D) The expression of MDR1 protein was analyzed by immunocytochemistry. (A) Control group; (B) hypoxia-treated group; (C) hypoxia- and control siRNA-treated group; (D) hypoxia- and HIF-1a siRNA-treated group. (E) Grading of positive protein staining in all 4 groups. HIF-1 $\alpha$, hypoxia-inducible factor 1 $\alpha$; siRNA, small interfering RNA; MDR1, multidrug resistance-1.

A

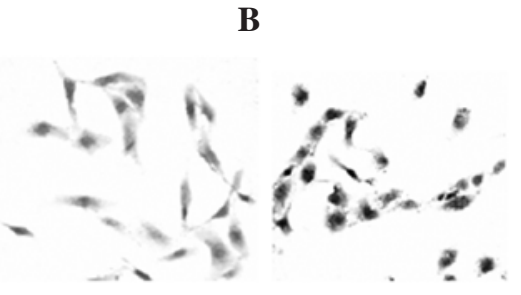

C

D

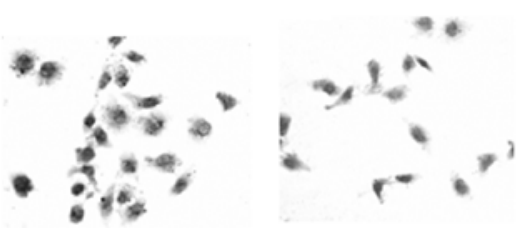

$\mathbf{E}$

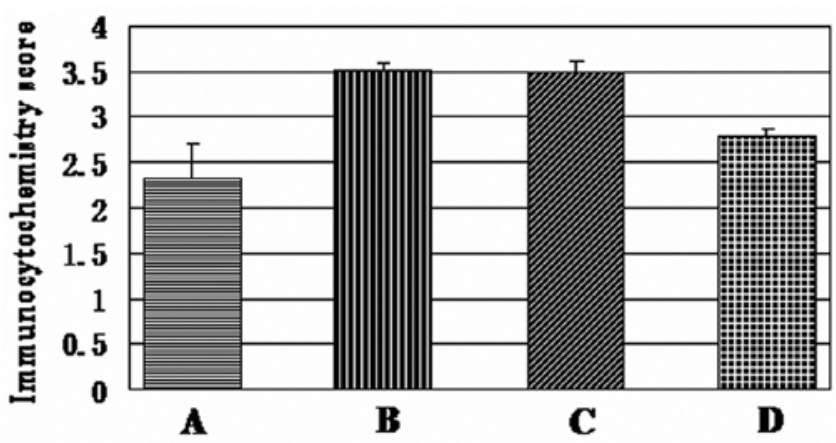

$\boldsymbol{M R P}$

Figure 5. The effects of hypoxia and HIF-1 $\alpha$ siRNA on expression of MRP protein in A549/CDDP cells. (A-D) The expression of MRP protein was analyzed by immunocytochemistry. (A) Control group; (B) hypoxia-treated group; (C) hypoxia- and control siRNA-treated group; (D) hypoxia- and HIF-1a siRNA-treated group. (E) Grading of positive protein staining in all 4 groups. HIF-1 $\alpha$, hypoxia-inducible factor 1 $\alpha$; siRNA, small interfering RNA; MRP, multidrug resistance-associated protein. 
correlated with that of MDR1 and MRP $\left(r^{2}=0.814\right.$ and 0.815 , respectively; $\mathrm{p}<0.05$ in each case).

Effects of hypoxia and HIF-1 $\alpha$ siRNA on the expression of HIF-1 $\alpha$ protein in A549/CDDP cells. HIF-1 $\alpha$ protein expression was analyzed by immunocytochemistry (Fig. 3). HIF-1a protein was expressed in all 4 treatment groups and was increased by hypoxia treatment. Treatment with HIF-1 $\alpha$ siRNA reversed the hypoxia-induced increases in HIF- $1 \alpha$ protein expression $(\mathrm{p}<0.05)$.

Effects of hypoxia and HIF-1 $\alpha$ siRNA on the expression of MDR1 protein in A549/CDDP cells. MDR1 protein expression was analyzed by immunocytochemistry (Fig. 4). MDR1 protein was expressed in all 4 treatment groups and was increased by hypoxia treatment. Treatment with HIF-1 $\alpha$ siRNA reversed the hypoxia-induced increases in MDR1 protein expression $(\mathrm{p}<0.05)$.

Effects of hypoxia and HIF-1a siRNA on the expression of MRP protein in A549/CDDP cells. MRP protein expression was analyzed by immunocytochemistry (Fig. 5). MRP protein was expressed in all 4 treatment groups and was increased by hypoxia treatment. Treatment with HIF-1 $\alpha$ siRNA reversed the hypoxia-induced increase in MRP protein expression $(\mathrm{p}<0.05)$.

\section{Discussion}

Although chemotherapy is an essential approach to treating lung cancer, MDR of lung cancer cells often leads to the failure of therapy. MDR is associated with multiple genes, most notably MDR1 and MRP (1). MDR1 plays essential roles in the absorption, distribution, metabolism and excretion of drugs, and affects drug resistance through decreasing the cellular concentration of chemotherapeutic agents (8). MRP functions as a transporter of GSH-X complexes and mediates the accumulation and excretion of drugs in cytoplasmic vesicles (4). HIF-1 $\alpha$ plays essential roles in the regulation of MDR1 and MRP, and may be induced in the hypoxic microenvironment of cancers (9). In the present study, we found that hypoxia increased the resistance of A549/CDDP cells to cisplatin and increased the expression of HIF-1 $\alpha$, MDR1 and MRP. Furthermore, increases in HIF-1 $\alpha$ expression were positively correlated with those of MDR1 and MRP. Consistent with our current findings, Wartenberg et al found that HIF-1 $\alpha$ expression was increased in cancer cells under hypoxic conditions, leading to the up-regulation of MDR1 (10). Furthermore, in A549 cells, a positive correlation between HIF- $1 \alpha$ and MDR1, and MRP expression has also been observed (4), suggesting that hypoxiainduced drug resistance in A549/CDDP cells may be due to the HIF-1 $\alpha$-mediated upregulation of MDR1 and MRP.

The recent emergence of RNA interference (RNAi) technology potentially provides a new approach for using gene therapy to bypass MDR in a number of types of cancer. Nieth et al used RNAi to inhibit MDR1 expression to 9\% in a human pancreatic cancer cell line (EPP85-181RDB) and a human gastric cancer cell line (EPG85-257RDB), and consequently decreased resistance to adriamycin to 11 and $42 \%$, respectively (11). Duan et al used RNAi to inhibit MDR1 expression in 2 human ovarian cancer cell lines (SKOV-3TR and OVCAR8TR) and decreased their resistance to taxol by 7- and 12.4-fold, respectively (12). In the present study, the results of the MTT assay revealed that hypoxia was capable of increasing the resistance of A549/CDDP cells to cisplatin and that this could be reversed by knocking down HIF-1 $\alpha$ with siRNA, with the relative reversal rate being $48 \%$. HIF-1 $\alpha$ siRNA also downregulated the expression of mRNA and protein for HIF-1 $\alpha$, MDR1 and MRP in A549/CDDP cells treated with hypoxia, indicating that the downregulation of HIF-1 $\alpha$ expression was capable of repressing the expression of MDR1 and MRP. Spearman analysis revealed that the expressions of HIF-1 $\alpha$, MDR1 and MRP was positively correlated. In conclusion, our study shows that hypoxia induces MDR in cancer cells and that this may be reversed by the siRNA knockdown of HIF-1 $\alpha$. These data suggest that RNAi, which targets HIF-1 $\alpha$, may be a useful approach to treating cancer in vivo.

\section{Acknowledgements}

This study was supported by grant no. 07JJ3055 from the Natural Science Foundation of Hunan, P.R. China.

\section{References}

1. Glaysher S, Yiannakis D, Gabriel FG, et al: Resistance gene expression determines the in vitro chemosensitivity of non-small cell lung cancer (NSCLC). BMC Cancer 9: 300, 2009.

2. Park S, Ha SY, Cho HY, et al: Prognostic implications of hypoxia-inducible factor-1alpha in epidermal growth factor receptor-negative non-small cell lung cancer. Lung Cancer 72: 100-107, 2011.

3. Comerford KM, Wallace TJ,Karhausen J,Louis NA, Montalto MC and Colgan SP: Hypoxia-inducible factor-1-dependent regulation of the multidrug resistance (MDR1) gene. Cancer Res 62: 3387-3394, 2002.

4. Xia S, Yu SY, Yuan XL and Xu SP: [Effects of hypoxia on expression of $\mathrm{P}$-glycoprotein and multidrug resistance protein in human lung adenocarcinoma A549 cell line]. Zhonghua Yi Xue Za Zhi 84: 663-666, 2004.

5. Wang G, Hazra TK, Mitra S, Lee HM and Englander EW: Mitochondrial DNA damage and a hypoxic response are induced by $\mathrm{CoCl}_{2}$ in rat neuronal PC12 cells. Nucleic Acids Res 28: 2135-2140, 2000

6. Milacic V, Chen D, Ronconi L, Landis-Piwowar KR, Fregona D and Dou QP: A novel anticancer gold(III) dithiocarbamate compound inhibits the activity of a purified 20S proteasome and 26S proteasome in human breast cancer cell cultures and xenografts. Cancer Res 66: 10478-10486, 2006.

7. Lu CD, Altieri DC and Tanigawa N: Expression of a novel antiapoptosis gene, survivin, correlated with tumor cell apoptosis and p53 accumulation in gastric carcinomas. Cancer Res 58: 1808-1812, 1998

8. Chen S, Huo X, Lin Y, et al: Association of MDR1 and ERCC1 polymorphisms with response and toxicity to cisplatin-based chemotherapy in non-small-cell lung cancer patients. Int J Hyg Environ Health 213: 140-145, 2010.

9. Kubo T, Sugita T, Shimose S, Matsuo T, Arihiro K and Ochi M: Expression of hypoxia-inducible factor-1alpha and its relationship to tumour angiogenesis and cell proliferation in cartilage tumours. J Bone Joint Surg Br 90: 364-370, 2008.

10. Wartenberg M, Gronczynska S, Bekhite MM, et al: Regulation of the multidrug resistance transporter P-glycoprotein in multicellular prostate tumor spheroids by hyperthermia and reactive oxygen species. Int J Cancer 113: 229-240, 2005.

11. Nieth C, Priebsch A, Stege A and Lage H: Modulation of the classical multidrug resistance (MDR) phenotype by RNA interference (RNAi). FEBS Lett 545: 144-150, 2003.

12. Duan Z, Brakora KA and Seiden MV: Inhibition of ABCB1 (MDR1) and ABCB4 (MDR3) expression by small interfering RNA and reversal of paclitaxel resistance in human ovarian cancer cells. Mol Cancer Ther 3: 833-838, 2004. 